\title{
RETHINKING LOCKEAN COPYRIGHT AND FAIR USE
}

\author{
SteVEn J. HoROWITZ*
}

[Two categories of criticism have recently been marshalled against Lockean copyright theory. Some argue that Locke's property theory offers no justification for intellectual property rights at all, while others suggest that Lockean rights in intellectual property are too strong. This article responds to each of these criticisms by offering a new Lockean approach to copyright that balances property rights for producers and fair use rights for the public. The approach relies most strongly on Locke's State of Nature/ Civil Society distinction and his dual concern for public and private rights.]

\section{INTRODUCTION}

As technology advances and the value of intellectual property increases exponentially, society is faced with difficult practical questions regarding the regulation of intellectual property rights. As these questions multiply, solving them on an ad hoc basis becomes more and more difficult, and so the search for theoretical foundations for intellectual property rights is on in earnest: by defining theoretical boundaries, we equip ourselves for emerging practical questions. In this paper, I advocate a distinctly Lockean approach to copyright law. I argue that Lockean copyright has the potential to be not only viable but also valuable.

Locke's property theory, from his Second Treatise of Government ${ }^{1}$ is a good source to draw from because it appeals to our moral intuitions in that it simultaneously respects public and private property rights. It is based on an initial common ownership of resources, and labourers gain private property rights in the fruits of their labour. This makes sense: no one ought to have preordained private rights in raw

\footnotetext{
* Diamond Scholar in Philosophy, Temple University, United States. The author wishes to thank Robert Guay, David Post, Paul Safier, Ned Diver, and Sarah Van Doel for their invaluable comments.

${ }^{1}$ John Locke, The Second Treatise of Government, in Two Treatises of Government (Peter Laslett ed., Cambridge Univ. Press 1988) (1698) [hereinafter LOCKE, SECOND TREATISE].
} 
materials, but individuals ought to earn property by working. Locke's work appeals both to moral intuition and to common sense, so it is hardly surprising that his property theory is adaptable to copyright.

Looking to Locke as a foundation for copyright is nothing new. ${ }^{2}$ But recently, critics have argued that Lockean intellectual property theory is untenable. ${ }^{3}$ Some suggest that a Lockean approach is self-contradictory. They argue that privatizing intellectual products undermines Locke's concern for public rights. Others accept its viability while rejecting it on normative grounds. These critics suggest that Lockean copyright is so strong as to preclude fair use, which is an essential part of good copyright law.

The aim of this paper is to present one cogent approach to Lockean copyright that resolves these relevant issues. That is, my approach will respond to the two main criticisms of Lockean theories by providing a viable Lockean framework for private copyrights while preserving the public's right to fair use. I do not argue that mine is the only way to solve the problems posed by critics of Locke. It is a sufficient response to the criticisms of Lockean copyright to show that there is at least one coherent Lockean approach that grants copyrights to producers while preserving the common sense fair use rights of consumers.

My approach relies most heavily on two aspects of Locke's text: 1) the distinction between the state of nature and civil society and 2) Locke's dual concern for public and private rights. The complex relationship in Locke's texts between natural and civil law will help respond to those critics who question the viability of a Lockean approach to copyright, while Locke's dual concern for public and private rights will be instrumental in aligning fair use with Lockean copyright.

In section II, I lay the groundwork for discussion, addressing intellectual property generally. In section III, I set out the basic features of Locke's property theory. In section IV, I turn to the critics, summarizing the criticisms marshalled against Lockean intellectual property theory and identifying how these criticisms still leave

\footnotetext{
${ }^{2}$ See generally Wendy J. Gordon, A Property Right in Self-Expression: Equality and Individualism in the Natural Law of Intellectual Property, 102 YALE L. J. 1533 (1993); Justin Hughes, The Philosophy of Intellectual Property, 77 GEO. L.J. 287 (1988); Adam D. Moore, A Lockean Theory of Intellectual Property, 21 Hamline L. Rev. 65 (1997) Lawrence C. Becker, Deserving To Own Intellectual Property, 68 ChI.-Kent L. Rev. 609 (1993); David McGowan, Copyright Nonconsequentialism, 69 Mo. L. REv. 1 (2004); William Fisher, Theories of Intellectual Property, in NEW ESSAYS IN THE LEGAL AND POLITICAL THEORY OF PROPERTY (Stephen R. Munzer ed., 2001) 168; Richard A. Spinello, The Future of Intellectual Property, 5 Ethics AND Information TeChNOLOGy 1-16 (2003); Stewart E. Sterk, Rhetoric and Reality in Copyright Law, 94 Mich. L. REV. 1197 (1996); Barbara Friedman, From Deontology to Dialogue: The Cultural Consequences of Copyright, 13 CARDOZO ARTS \& ENT. L.J. 157 (1994); Lloyd L. Weinreb, Copyright for Functional Expression, 111 HARV. L. REv. 1150 (1998); Benjamin G. Damstedt, Note, Limiting Locke: A Natural Law Justification for the Fair Use Doctrine, 112 YALE L.J. 1179 (2003).

${ }^{3}$ See Seana Valentine Shiffrin, Lockean Arguments for Private Intellectual Property, in NEw ESSAYS IN THE LEGAL AND POLITICAL THEORY OF PROPERTY, supra note 2, at 138 (2001); Samuel E. Trosow, The Illusive Search for Justificatory Theories: Copyright, Commodification and Capital, 16 CAN. J.L. \& JURIS. 217 (2003); Shubha Ghosh, Deprivatizing Copyright, 54 CASE W. RES. L. REV. 1 (2004); Carys J. Craig, Locke, Labour and Limiting the Author's Right: A Warning Against a Lockean Approach to Copyright Law, 28 QUEEN's L.J. 1 (2002).
} 
room for a new approach. In section V, I build a Lockean theory that allows for fair use, followed by some concluding remarks in section VI.

\section{INTElectual Property Theory}

Before turning to Locke to initiate a discussion of Lockean copyright, I will address intellectual property in general, both to clarify how I use certain terms as well as to locate this project within the scope of the field.

There are many differences between intellectual products and tangibles ones. For example, while there is only one Statue of Liberty, any online digital music store can sell you the exact same digital copy of "Let It Be." If someone made a copy of the Statue of Liberty, it would not be the same as the original. But you can burn thirty copies of "Let It Be" and give them to your friends with no loss of quality. Also, identifying exactly what an intellectual property right in "Let It Be" consists in is more complicated than dealing with statues. It is hard enough to identify exactly what the intellectual product is.

Because an infinite number of people can simultaneously use and enjoy an intellectual product without diminishing its usefulness, intellectual property is nonrivalrous. Thomas Jefferson provides a useful analogy for this quality: "He who receives an idea from me, receives instruction himself without lessening mine; as he who lights his taper at mine, receives light without darkening me." ${ }^{4}$ That intellectual property is nonrivalrous raises a question as to whether governments should grant private intellectual property rights at all. Rather than arguing over who owns a certain song, we could just as easily just go home and listen to it. But our society values intellectual property, so we need to examine such rights carefully.

Intellectual property comprises four distinct parts: patent, copyright, trademark, and trade secret. In this paper, I focus on copyright, though I suspect that at least some of my Lockean copyright theory would adapt to patent as well. US copyright law protects "original works of authorship fixed in any tangible medium of expression." Though it protects expressions of ideas, it does not protect ideas themselves. ${ }^{6}$ Owners of copyright have the exclusive right to reproduce, perform, display or transmit their work. ${ }^{7}$

But this exclusive right does not preclude all public uses of a given work. The public has a right to fair use of copyrighted works, which allows for:

[The] use of a copyrighted work, including such use by reproduction in copies or phonorecords...for purposes such as criticism, comment, news reporting, teaching...scholarship, or research. ${ }^{8}$

\footnotetext{
${ }^{4}$ Letter from Thomas Jefferson to Isaac McPherson (Aug. 13, 1813), in THE LIFE AND SELECTED WRITINGS OF THOMAS JEFFERSON (Adrienne Koch and William Peden eds., 1944), at 630. 
The fair use doctrine gives the public access to products that they do not own. In doing so, the fair use doctrine limits private intellectual property rights. Were it not for fair use, I might have the right to prohibit negative commentaries of this paper, for example- at least those that use my expression to buttress their criticism.

Fair use is an important part of copyright. Copyright serves "[t]o promote the progress of science and useful arts, by securing for limited times to authors and inventors the exclusive right to their respective writings and discoveries." "Fair use helps to promote this end. Entire fields, such as film criticism, depend on free access to copyrighted materials. Were it not for fair use, there would be little room for such fields. Because it is so important, any copyright theory that prohibited fair use would for that reason be unattractive.

\section{LOCKE's PROPERTY THEORY}

In this section, I provide a basic outline of Locke's property theory in order to distil those elements that are most fundamentally Lockean from Locke's text. These elements provide the framework for my Lockean copyright theory. I begin, as Locke does, in the state of nature, explaining how civil society is built out of natural law. Then, I distinguish two main aspects of Locke's property theory: the natural law justification for property rights and the mechanism through which property rights are attained. I explain why the natural law justification is not essential to a discussion of copyright in civil society. Then I focus on Locke's appropriation mechanism, which provides the main framework for my Lockean copyright theory. The appropriation mechanism involves consideration of the natural common, labour-desert property rights, and limits on the acquisition of private property. Finally, I discuss Locke's underlying dual concern for public and private rights.

Before discussing Locke's theory, I should clarify some key terms to avoid confusion. By appropriation, I do not mean merely the act of obtaining a given good. Instead, appropriation is the process by which one gains property rights in a good. What exactly such property rights ought to consist in-according to Locke or otherwise-is an important question. But since it is a complex issue in itself that is not at the core of this project, I will offer a very basic account. ${ }^{10}$ A property right in a product includes the right to exclude others from using or accessing that product without consent of the owner. Further, property rights allow owners to make any use of a given product that they please, provided that their use does not harm others. This account of what property rights consist in is incomplete, but it should provide the framework for understanding the core of this project.

\footnotetext{
${ }^{9}$ U.S. CONST. art. I, $\S 8$, cl. 8.

${ }^{10}$ For a more complete discussion of Lockean property rights, see Adam Mossoff, What Is Property? Putting The Pieces Back Together, 45 ARIZ. L. REV. 371 (2003), at 385-91.
} 


\section{A The State of Nature and Civil Society}

Locke's Second Treatise begins in the state of nature, which he describes as a "State of perfect Freedom." "In this state, there is no government to regulate one's actions, and there is no system that judges or punishes. Each person has an equal right to carry out the mandates of the state of nature. ${ }^{12}$ Locke uses this state as a vehicle for his discussion of natural law: even where there is no government, natural law still applies. ${ }^{13}$ Natural law is the law of reason, which commands that "no one ought to harm another in his Life, Health, Liberty, or Possessions." law also allows for property rights: ownership does not require a deed.

Natural law informs and limits the scope of civil law-that is why Locke starts a treatise of government with the state of nature. He begins his discussion by saying, "To understand Political Power right, and derive it from its Original, we must consider what State all Men are naturally in." ${ }^{15}$ But natural law is much more than a precursor to civil law. Locke later states:

The Obligations of the Law of Nature, cease not in society, but only in many Cases are drawn closer, and have by Humane Laws known Penalties annexed to them, to enforce their observation. ${ }^{16}$

So the state of nature is much more than some mythical forebear to civil society. Instead, it provides the natural law framework that governments must abide.

At the same time, civil law need not be identical to natural law. While legislation is always bound by natural law, civil law goes beyond natural law in some important ways. In the state of nature, for example, there are no impartial judges to resolve disputes. This is one reason why people form societies. ${ }^{17}$ Society can set up a judicial system. Society can produce innumerable laws, provided that they are for the "public good of Society." 18 So even if copyright is not part of Locke's natural law framework, it still can be part of civil society.

\section{B Natural Law Justification for Private Property Rights}

Locke's property theory comprises two parts. The first is his natural law justification for private property rights. All the resources of the world are initially the common property of humanity. ${ }^{19}$ Private appropriation occurs at the expense of the common, and so the question is this: how does one justify, in the state of nature, private property at the expense of the public's initial common ownership?

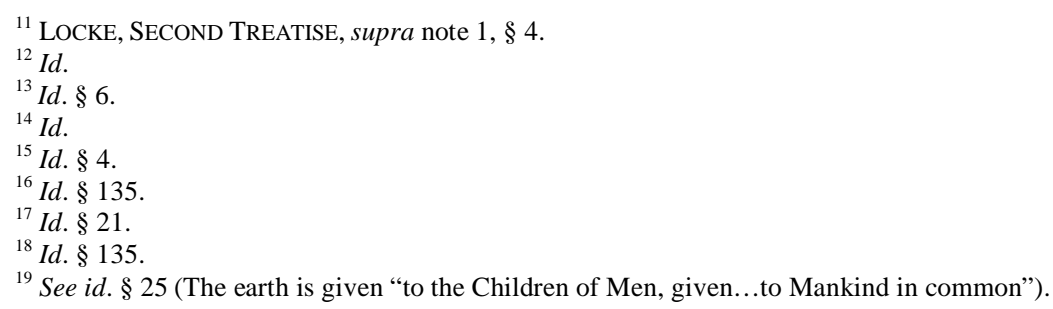


Locke provides several answers to this question. ${ }^{20}$ These justifications apply to the state of nature: they explain how, without any form of society or civil law, one justifies private property rights. If a government already recognizes the utility or necessity of property rights, irrespective of natural law considerations, one need not justify such rights. Locke's natural law justification for private property plays an important role within his theory, particularly as it responds to the work of his contemporary Robert Filmer. ${ }^{21}$ But I am not interested here in discussing whether copyrights should exist at all, so justification is beyond the scope of this project.

\section{The Lockean Appropriation Mechanism}

The second part of Locke's property theory is his mechanism for the appropriation of goods held in common. This mechanism responds to the practical question of how one earns a private property right in goods taken from the common. The mechanism consists of three parts: 1) the common, 2) a labour-desert appropriation scheme for drawing from the common, and 3) limits on what one can take from the common.

The first part of Locke's mechanism is the natural common. For Locke, "The Earth, and all that is therein, is given to Men for the Support and Comfort of their Being." 22 The natural common is the entire world of unappropriated materials. These unappropriated materials are the resources of the world in their natural state. The common was given to humanity "for their benefit, and the greatest Conveniences of Life they were capable to draw from it." 23 So while the common is the property of humanity, it is meant to be used.

The second part of the appropriation mechanism is labour-desert appropriation. One must labour in order to appropriate some part of the common. Locke describes appropriation in this way:

Whatsoever then he removes out of the State that Nature hath provided, and left it in, he hath mixed his Labour with, and joined to it something that is his own, and thereby makes it his Property. ${ }^{24}$

\footnotetext{
${ }^{20}$ Locke's answers include necessity and desert. Regarding necessity, see LOCKE, SECOND TREATISE, supra note $1, \S 26$ ("There must of necessity be a mean to appropriate [natural resources]...before they can be of any use"). Regarding desert, see LOCKE, SECOND TREATISE, supra note 1, § 27 ("Whatsoever then he removes out of the State that Nature hath provided... he hath mixed his Labour with, and joined to it something that is his own, and thereby makes it his Property"). For a more complete account of Locke's several justifications, see Fisher, supra note 2, at 21-2.

${ }^{21}$ See Sir Robert Filmer, Patriarcha, in PATRIARCHA AND OTHER POliticAl WORKS OF SIR RobERT FILMER 47-126 (Peter Laslett ed., 1949) (1680). (Filmer's project is to justify the rights of monarchs as descendants of Adam.)

${ }^{22} I d . \S 26$.

${ }^{23} I d . \S 34$.

${ }^{24}$ Id. $\$ 27$.
} 
In labouring, one distinguishes particular goods from the common and gains property rights in those goods. This is why Locke's theory is called a "labour-desert" theory of property: one is justly rewarded for labouring,

The passage above reveals not only the sufficient condition for appropriation, but also what Locke means by "labour." Labour is the activity of removing something out of its natural state and distinguishing it from the common. Locke later adds "[t]hat labour put a distinction between them [appropriated goods] and the common." 25 Labour is merely the process of putting a distinction on particular goods. If you remove something from its natural state, then you have laboured, and your labour is rewarded with property rights in that thing.

The third part of Locke's appropriation mechanism is the set of limits on appropriation. It may be objected that, under Locke's mechanism, "any one may ingross as much as he will." ${ }^{26}$ Locke provides two limits in response to this objection: the spoilage proviso and the "enough and as good" proviso.

Locke's spoilage proviso mandates that one may not have property rights in excess of that which he can use before spoilage. The basic argument is that one should not be wasteful at the expense of others. This is how Locke describes the limit of appropriation:

As much as any one can make use of to any advantage of life before it spoils; so much may he by his labour fix a Property in. Whatever is beyond this, is more than his share, and belongs to others. ${ }^{27}$

This limit on appropriation is called the spoilage proviso because it requires that appropriated goods are used before they spoil. The spoilage proviso says that it is wrong to hoard up millions of apples while your neighbour starves, and Locke's property theory does not recognize property rights in those apples that you cannot use before they spoil.

Locke's "enough and as good" proviso limits appropriation by requiring that the common not be overly depleted. Locke does not explicitly state this as a proviso, but it emerges from the following:

For this Labour being the unquestionable property of the Labourer, no Man but he can have a right to what that is once joined to, at least where there is enough, and as good left in common for others. ${ }^{28}$

One can appropriate as much as she likes, so long as she does not leave the common depleted beyond this "enough and as good" standard. ${ }^{29}$ "Enough and as good" is a two part proviso. The "enough" requires that labourers not overly deplete the common quantitatively —one must not take so much that there is too little left for others. The "as good" part is a qualitative measure that prohibits labourers from

\footnotetext{
${ }^{25} I d . \$ 28$.

${ }^{26} I d . \S 31$.

${ }^{27} I d . \S 31$.

${ }^{28}$ Id. \$ 27.

${ }^{29}$ There is some debate as to whether this proviso should be considered a proviso at all. See, e.g. Jeremy Waldron, Enough and as Good Left for Others, 29 PHIL. QUART. 319 (1979).
} 
justly appropriating all the best resources, leaving the common with lesser materials.

The specifics of these limits are not as important as the more general descriptive point: Locke's theory limits private appropriation. In limiting private appropriation, Locke reveals his concern for the public's right to a common. The common ought to provide sufficient resources for humanity. That there are limits is more significant than the specific limits themselves because it is unlikely that the specific limits can easily be adapted to an intellectual property theory. Tangible goods are very different from intellectual products. Therefore, it is unlikely that limits specifically conceived for tangible goods will be adaptable to the complexities of intellectual property. But the general concern can be adapted: appropriation ought to be limited in order to preserve a robust common.

In summary, Locke's appropriation mechanism comprises three parts: the common, labour-desert appropriation, and limits on appropriation. The world of resources is shared in a common, but by labouring we individually appropriate goods from the common. This labour is an act of distinguishing part of the common-which becomes one's property-from the resources that continue to be held in common. Various provisos limit our appropriation so that we do not overly deplete the common

Locke's mechanism embraces a dual concern for the private rights of the individual in property and the public rights in a natural common of resources. The mechanism accounts for private rights by providing individuals access to the common and a way to appropriate goods from the common. At the same time, it accounts for public rights by granting equal ownership of the common and limiting private appropriation so as to not encroach too far on public rights. This dual concern is fundamental in Locke's text, and therefore it should be a basic consideration in developing a Lockean intellectual property theory.

\section{APPARENT SHORTCOMINGS OF Lockean INTELlectual PROPERTY THEORY}

In this section, I outline the dominant criticisms of Lockean intellectual property theory. The criticisms generally fall into two categories. The first category of criticism focuses on the weakness of any Lockean intellectual property theory. The basic premise is that there is no way to overcome certain aspects of Locke's text that render a Lockean approach to intellectual property weak or impossible. The second category of criticism focuses on the strength of Lockean theory. This view is that Locke's text provides a foundation for individual property rights that is so strong as to cripple the public's right in a robust intellectual common. I show each of these sets of criticism is more directly attached to Locke's text than to Lockean copyright in general. As a result, they leave room for a new approach to Lockean copyright.

One suggested hurdle for Lockean theory is that it cannot be applied to intellectual products because Locke's interest in the public right to a robust common outweighs 
potential private intellectual property rights. This perspective emerges out of an awareness of the nonrivalrous character of intellectual property: intellectual products can be used without being individually appropriated because we do not need a property right to use any intellectual products that are necessary for our subsistence. Therefore we do not need a property right to use any intellectual products that are necessary for our subsistence. Granting intellectual property rights, while unnecessary for subsistence, can potentially diminish common resources, so such rights cause a net loss in public resources. And since they are unnecessary, they are unjustified. The Lockean theorist must seek out other theoretical foundations for intellectual property.

Seana Shiffrin argues that Locke's strong focus on public rights precludes anything more than weak private intellectual property rights. ${ }^{30}$ Due to the lack of natural law justification for intellectual property, she concludes, "The place of common ownership in Locke's scheme cuts against the argument for private ownership of intellectual property." 31 Shiffrin argues that the "fully effective use of an idea...generally does not require, by its nature, prolonged exclusive use or control."32 Since one need not appropriate intellectual products in order to effectively use them, Locke's natural law justification for property rights does not apply to intellectual products. As a result, copyright cannot be part of a Lockean framework.

There is a solution to the problem that Shiffrin's reading poses, however. The solution lies in the complexities of Locke's text. One could grant that the state of nature does not provide apparent justification for copyright and still embrace copyright in civil society. If a government recognizes copyright as good for society, then it can legislate to protect copyright. While the use of an intellectual product may not require appropriation, there may be some reason other than necessity to justify copyright as good for society.

The text leaves room for other responses to Shiffrin as well. Her interpretation focuses on just one of Locke's natural law justifications for private property, namely the "necessary-for-use" justification, which justifies appropriation through necessity. ${ }^{33}$ Many argue that the necessary-for-use justification is not even the most significant one. ${ }^{34}$ Lockean theory is often called labour-desert theory for a reasonLocke justifies property rights as a deserved reward for labourers. Shiffrin is aware that she is in the minority when she suggests, "Labour plays a subsidiary role [in Lockean property theory.]" 35 What she means here is that labour identifies, but does not justify, property claims. Labour is only the mechanism by which, for example, Bob's property (which he owns merely out of necessity) is distinguished from Otto's (also of necessity). If Shiffrin had not thus reduced the role of labour

\footnotetext{
${ }^{30}$ Shiffrin, supra note 3; See also Trosow, supra note 3 (expanding on Shiffrin's position).

${ }^{31}$ Shiffrin, supra note 3 , at 166-7.

${ }^{32} I d$. at 156.

${ }^{33}$ LOCKE, SECOND TREATISE, supra note $1, \S 26$ ("There must of necessity be some means to appropriate [the resources given to humanity in common]...before they can be of any use.").

${ }^{34}$ See, e.g., McGowan, supra note 2, at 38 (focusing on self-ownership and labour-desert); Hughes, supra note 2; Becker, supra note 2.

${ }^{35}$ Shiffrin, supra note 3 , at 143.
} 
in her interpretation of Lockean theory, she would not have been so successful in limiting private rights that intellectual property rights disappeared.

A third way to respond to Shiffrin's indictment of Lockean intellectual property theory is to cite Locke's dual concern for the individual and the public. Locke's text is simultaneously focused on the rights of humanity and on the rights of each individual person. For Locke, individual rights are not merely unfortunate necessities, but instead are naturally bestowed upon each person in the same way that the natural common is given to all persons. Locke suggests that society helps to ensure our private rights, saying "The great and chief end... of Men uniting into Commonwealths, and putting themselves under Government, is the Preservation of Property." 36 While Locke is committed to private property rights in various ways, Shiffrin overly emphasizes ownership and public rights at the expense of the individual.

William Fisher presents a different type of argument against the viability of a Lockean approach to intellectual property theory. ${ }^{37}$ He claims that "it is not altogether clear that the labour theory supports any sort of intellectual-property law," citing textual ambiguities as the source of the problem. ${ }^{38}$ For example, Fisher lists six different justifications for property rights from Locke's text, and he argues that "whether Locke's theory provides support for intellectual property depends on which of these various rationales one regards as primary." 39 His argument, then, is this. Locke provides several different justifications for property. The different justifications can lead in different directions. These different directions represent a problem for Lockean theory because they would produce an approach to intellectual property law that is so ambiguous as to be useless. A well-formed approach is necessarily as precise as possible because imprecision can lead either to conflicting policies or to no foundation for policies at all. Therefore, Lockean intellectual property theory is crippled by ambiguity. From the ambiguities that Fisher identifies, he infers that the choices we make in our approach to Lockean intellectual property theory, "will often make a big difference." 40 And since Locke's text provides no unequivocal foundation, it cannot produce a viable approach to intellectual property.

While I agree that Locke is often ambiguous, that does not imply that the ambiguities in Locke's text stop us from producing a viable Lockean intellectual property theory. Fisher's claim is that the interpretations one chooses for what counts as labour and what constitutes the intellectual common matter. This is true. But ambiguity alone does not destroy Lockean copyright theory. There are numerous examples of theories that are ambiguous that nevertheless produce viable solutions to complex problems. Take, for example, a basic account of retributive punishment. Advocating that criminals be punished in order to "repay" their crimes proportionally according to severity is an ambiguous policy. One might ask, how much does a

\footnotetext{
${ }^{36}$ LOCKE, SECOND TREATISE, supra note $1, \S 124$

${ }^{37}$ Fisher, supra note 2.

${ }^{38} \mathrm{Id}$. at 184 .

${ }^{39} \mathrm{Id}$. at 185 .

${ }^{40}$ Id . at 186 .
} 
criminal "owe" for any given crime? An advocate of retributive justice could give many different accounts of how much a criminal owes society, and it does make a difference which account one chooses. But retributive punishment is still a viable option for dealing with criminals despite its ambiguity. One merely needs to choose which account she wants to adopt. Fisher's argument raises an important point: the Lockean intellectual property theorist has some important decisions to make. But there is still room to make those decisions.

Fortunately, the ambiguity in Locke is not as bad as it could be. If Lockean theory were so ambiguous as to be completely uninformative, then that would render it practically useless as an approach to copyright. But Fisher insists the opposite, in asserting that the theory has too many practical consequences. His argument is that the myriad practical consequences are themselves inconsistent, or, what is even weaker, that people can read the text in many different ways. That people read a text in many ways is not a criticism of the text itself, however: it is equally possible that the text is fine and all but one reading is wrong.

In developing a Lockean intellectual property theory, one should be as true as possible to that which is most fundamentally Lockean while structuring the roles of labour and the common in the most desirable way. Any problems in Locke's text are both immaterial and unsurprising. They are immaterial because Lockean property theory is distinct from Locke's text. They are unsurprising because Locke does not specifically address intellectual property at any point in his Two Treatises.

While both Shiffrin and Fisher highlight important concerns, their arguments do not put an end to the project of Lockean copyright. Shiffrin's reading highlights the common. And this is important: a copyright theory is not Lockean unless it presupposes a natural intellectual common. Fisher cites the difficult choices one must make within a Lockean framework. Indeed there are choices that one must make, and indeed I will do so in what follows.

The second category of criticism of Lockean intellectual property theory emerges out of a concern for fair use. Scholars fear that Lockean theory rewards the intellectual labourer with property rights that are too exclusive. They suggest that any reasonable intellectual property theory should protect the public's right to quote from, parody, or criticize an intellectual product, and they argue that Locke's theory grants private rights that are so strong as to preclude such public uses. But though these concerns have a distinct presence in the literature, it is difficult to find them fully articulated by anyone.

The absence of developed arguments against Lockean copyright theory on fair use grounds is indicative of the inherent weakness of this line of criticism. It is difficult to find a scholar who devotes any substantial effort to supporting the position that Lockean theory overly limits fair use: instead, one finds some who respond to this apparent problem and others who accept the problem as a given. The general fear of a diminishing common is a real one, and it is most notably articulated by Robert Nozick, who is concerned that Lockean theory might give the ocean to anyone with 
a can of tomato juice. ${ }^{41}$ But Lockean theory does not necessitate such absurd privatization, and Nozick's concern is not that the tomato juice problem renders Lockean theory untenable. Instead, Nozick tries to provide his own Lockean property theory that passes the tomato juice test. Still, many have used Nozick to fuel their Lockean criticisms.

David McGowan does a good job of characterizing these criticisms of Locke, though he is not an advocate of them. ${ }^{42}$ He poses the problem this way:

If I am right to say that Lockean theory justifies granting authors the right to exclude others from their works, then...it is very hard to square existing fair use rights, or any other set of fair use rights, with Lockean theory. That is troubling, because my hunch is that some level of fair use rights increases welfare, meaning that a pure Lockean copyright would impose welfare losses. $^{43}$

McGowan is not really outlining the argument that Lockean theory does not allow for fair use-he is just explaining that it seems like Lockean theory has this problem, and that such a problem is "troubling." The implied argument runs like this: Lockean theory justifies the right to exclude others from using a privately owned intellectual product. Excluding others implies excluding what we consider fair uses of a product. Thus, Lockean theory does not allow for fair use. The form of the argument appears to be valid, and it is supported by Locke's text in that Lockean property rights appear to justify excluding others from one's property.

Fortunately, Locke's property theory is not as rigid as this argument makes it out to be. The relationship between the state of nature and civil society is evidence of its pliability. In the state of nature, one has an exclusive right to one's own land-she can keep all others off it and even punish trespassers. But a civil society can deem it in the best interests of society that some people have access to her land even without her consent. For example, society might create a law that allows police officers to follow criminals onto her land in order to ensure the safety of society. This is not part of natural law, but, beyond making intuitive sense, this is part of Lockean property theory. Lockean civil society is structured so that each person "authorizes the Society...to make Laws for him as the Publick good of the Society shall require." 44 If the public good justifies limiting the exclusivity of property rights in civil society, then we need not rigidly adhere to that aspect of natural law. Fair use might limit the scope of copyright, but if it limits it for the good of society, then it accords with Lockean theory.

\footnotetext{
${ }^{41}$ ROBERT NOZICK, ANARCHY, STATE AND UTOPIA 175 (1974) ("If I own a can of tomato juice and spill it in the sea so that its molecules...mingle evenly throughout the sea, do I thereby come to own the sea?").

${ }^{42}$ McGowan, supra note 2, at 51 (McGowan presents this line of criticism as a possible utilitarian objection, which he dismisses on the grounds that Lockean theory can be used as a foundation for intellectual property theory without adhering as rigidly to Locke's text as this line of criticism might suggest).

${ }^{43}$ McGowan, supra note 2, at 51.

${ }^{44}$ LOCKE, SECOND TREATISE, supra note $1, \S 89$.
} 
Both categories of criticism - that a Lockean approach is incongruous with intellectual property and that such an approach leaves no room for fair use-highlight some important concerns for the Lockean intellectual property theorist. But neither category eliminates the possibility of Lockean copyright. Those critics that challenge the viability of Lockean theory remind the intellectual property theorist that initial common ownership is essential to Lockean copyright. Those that reject Lockean copyright because they fear it is too strong highlight the importance of fair use. By drawing on these criticisms, one can create an informed, attractive approach to Lockean copyright.

\section{CONSTRUCTING A LOCKEAN THEORY THAT LEAVES ROOM FOR FAIR USE}

In this section, I provide a new framework for Lockean intellectual property theory. This framework relies on the fundamental Lockean dual concern for the individual and the public and the basic structure of Locke's property theory. I develop a Lockean approach to the seemingly intractable issues in intellectual property theory: the intellectual common, appropriation, and limits on appropriation. By advancing a framework that is sensitive to the differences between tangible and intellectual products, while maintaining Lockean commitments, I thus demonstrate the viability of a Lockean approach to copyright.

Locke's property theory begins with the natural common. The common is the entire world of resources in their natural state. The common is significant because, rather than being given as a divine right to a few individuals, it is a world of resources owned by humanity in common. By building his property theory upon a natural common, Locke deemphasizes individual rights and recognizes public rights. The role of the common within Locke's theory is that of a universal baseline: we all start off with the equal property rights in the world. Individual property rights are then gained through rightful acts of appropriation, but everyone has an equal innate claim to the world.

Locke's common does not appear to be easily adaptable to an intellectual property theory. The difficulty lies in the ontology of intellectual products. While the natural resources from which a tangible good is produced are identifiable, it is much more difficult to discern the resources from which an intellectual product is produced. For example, what are the resources from which Beethoven's Symphony No. 5 was produced? There are innumerable answers to this question. ${ }^{45}$ There are the technical answers: a particular set of motives and chord progressions, the symphonic form, or western harmony. But there are also the more romantic answers: sounds Beethoven heard in nature, feelings that he had, or his experiences. None of these fully answer the question of natural materials, not in the same way that one might be able to answer the question, "Where did this piece of paper come from?"

\footnotetext{
${ }^{45}$ I consider just two types of answers for the purposes of explication, though I recognize that many possible answers are of neither type.
} 
This is because intellectual products are different from tangible goods. There is no apparent set of resources from which intellectual products are produced.

There are several inadequate ways of thinking about the intellectual common. For example, the common could be the set of all possible intellectual products, or to put it another way, any intellectual product or idea that has been or will ever be produced. On this perspective, Beethoven's symphony is merely a product drawn from the common. Beethoven, in some sort of divinely inspired moment, transcribed the symphony from the intellectual common to the world. But this view is unsatisfactory for two reasons. First, it is contrary to our natural intuitions. It just does not make sense to say that Beethoven's symphony existed in the intellectual common before he produced it. Second, the common that this view portrays does not really resemble the Lockean common, because it is overdeveloped. The Lockean common is an uncultivated world rather than a world of infinite cultivated products.

Another inadequate way of thinking of the Lockean intellectual common is the opposite of the first one. On this view, the intellectual common is empty: all intellectual products come from intellectual resources within the individual himself. This avoids the problem of disputes over natural intellectual resources: because they come from the individual, no one else any claim to them. But this view of the common is equally untenable. First, there is not a common if the common is empty. The view circumvents the Lockean concern for the public in that it grants no common resources. Second, it does not make sense. Lacking any raw materials from which to build intellectual products, producers are left with nothing to produce. If Beethoven had been placed in isolation-from contact with humans as well as contact with human culture-he would never have written any symphonies.

There is a better way to conceive of the intellectual common: the common consists of the resources for the production of intellectual products and not the products themselves. ${ }^{46}$ This aligns well with the so-called idea/expression dichotomy. ${ }^{47}$ The ideas that inspire the production of intellectual products are commonly owned, whereas the individual expressions - the particular poem, painting, or song-are not part of the natural intellectual common.

This conception of the common embraces Locke's dual concern for private and public rights. The public's right to a common is met with a robust set of intellectual resources: anyone can access forms, languages, and general ideas. No one can hinder this natural right. At the same time, this concept preserves private rights in that intellectual products are subject to property rights. So while you cannot own the English language, you can own a work written in that language. This arrangement accounts for both private and public rights.

Some might object that this conception of the intellectual common cannot be applied in practice because the idea/expression dichotomy is not always clear. In most cases, however, it will be easy to distinguish ideas from expressions. And if a

\footnotetext{
${ }^{46}$ For other perspectives on the intellectual common, see Hughes, supra note 2, 315-26; Fisher, supra note 2, at 186-9.

${ }^{47}$ For a discussion of the idea/expression dichotomy, see Abraham Drassinower, A Rights-Based View of the Idea/Expression Dichotomy in Copyright Law, 16 CAN. J.L. \& JURIS. 3 (2003).
} 
product is an expression, then it is not part of the intellectual common. Sometimes it might be hard to tell the extent to which an intellectual product is actually an expression rather than merely an idea. For example, consider a musician who records a single note-with nothing distinct about it - on the piano. The note itself is part of the intellectual common: it is a raw material that, combined with other materials, musicians use to create unique expressions. But at the same time, this particular musician used this note alone to express herself. The idea/expression dichotomy seems to blur. This is a hard case, but my framework is not designed to solve all the hard cases. Instead, it should provide a general normative framework for deliberation. It is even advantageous that this framework does not solve all the hard cases: it leaves room for an analysis of the complexities of individual cases instead of mandating adherence to a set of inflexible rules.

Others might argue that this conception works, but it is not worth adopting because it does not provide sufficient public intellectual materials. But this conception gives the public plenty of resources. Of course, we are given basic materials such as language and forms, but we also can use as resources any intellectual materials except particular expressions. So we can be inspired by, or create in a similar style as, anyone and anything at all. The only thing we are deprived of is the unhindered ability to use the particular expressions themselves as materials for the creation of intellectual products. Thus, this conception of the intellectual common is rich with resources.

There are some consequences of adopting this conception of the common. First, no one has a greater natural claim to ideas than anyone else. No one can justly claim natural property rights in the idea of a love song, for example. Even if we could identify the inventor of the love song as a category, that person would not have an intellectual property right in the idea of a love song. The idea of a love song does not meet the threshold for assigning property rights. And it shouldn't: we do not tend to think that any individual or group should be privileged with respect to access to forms of intellectual expression and the like.

A second consequence of this conception of the intellectual common is that particular expressions are subject to private ownership. While he may not own the general form of reality television or the idea of having a show about a job competition, Donald Trump can own the rights to The Apprentice, his own particular intellectual product. And he should. The show is a unique expression of the idea of a competitive reality show. This coheres with out moral intuition that when someone is responsible for the creation of a particular product, that person ought to own the product of his labour.

The best way to conceive of the intellectual common, then, is to view it as comprising the ideas rather than particular expressions. Ideas are not naturally subject to private property rights. Expressions, or intellectual products, are subject to such rights. This view embraces Locke's dual concern for public and private. Also, while appropriation is not at issue here, this conception of the common leaves room for private ownership of intellectual products, since the common is limited to ideas and does not include particular expressions. 
Locke's mechanism for appropriation is built upon labour-desert. The labourer is rewarded with property rights in the fruits of her labour. Lockean "labour" is best understood as any activity with a distinguishing function, rather than in the more everyday sense of the word "labour." That is, labour is the act by which one distinguishes a particular good or set of goods from the natural common. By defining Lockean labour in this way, one alleviates the problem of what qualifies as labour. Any act can be considered labour, so long as it distinguishes goods from the common.

Critics have been sceptical as to whether a Lockean labour-desert theory could possibly be adapted to an intellectual property theory. One problem, they say, is that the idea of "labour" does not seem to apply in the same way to writing poetry as it does to ploughing. Also, some suggest that appropriating intellectual products goes against Locke's concern for the public: they say that such appropriation is needless and does the public harm. But both of these sets of criticism overlook the flexibility of Lockean intellectual property theory as well as its fundamental concerns. There is a way to conceive of a Lockean labour-desert mechanism for the appropriation of intellectual products from the common.

This view of labour as a distinguishing function, while allowing for the appropriation of expressions, precludes the direct appropriation of ideas and intellectual resources from the common. This is important: were intellectual labourers able to appropriate ideas themselves, the intellectual common might become overly depleted. But one need not worry about that within a Lockean framework because any attempt to appropriate ideas from the common will fail to count as labor- labor requires sufficient distinction of an expression form the intellectual common of ideas. For example, if someone tried to appropriate the musical form of the Blues, then a Lockean labour-desert scheme would require that she sufficiently distinguish her appropriated product from the intellectual common. But since the form of the Blues is part of the common, then the form itself cannot be distinguished from the common. As a result, the Blues cannot be appropriated.

The intellectual labour that produces an expression can be rewarded with property rights in that expression. As long as the labour sufficiently distinguishes ${ }^{48}$ a particular expression from the intellectual common, that expression becomes the property of the intellectual labourer. So if someone paints a portrait, then she is rewarded with property rights in her product, the portrait. She does not come to own the idea of painting a portrait, nor the idea of using particular materials to create a portrait.

The view of labour as that which distinguishes particular goods from the common allows multiple people to independently appropriate very similar or even identical goods from the common. Appropriation does not require that one distinguish her expression from other expressions, but only that she distinguish her product from the common. This may seem to be an odd consequence, but it fits squarely with U.S. copyright law. In America, if two songwriters independently draw from the

\footnotetext{
${ }^{48}$ What such sufficient distinction consists in depends on the type of intellectual product. There is room for deliberation here, and the specific guidelines are beyond the scope of this paper.
} 
intellectual common to write two identical songs, them each artist gains a property right in his work. Thus Lockean labor-desert, defines as I have defined it, conforms to this interesting aspect of existing copyright law.

Shiffrin contends that a Lockean framework prohibits such strong private intellectual property rights because they undermine Locke's concern for the rights of humanity. ${ }^{49}$ Even if one accepts that Locke's concern for humanity outweighs his concern for the individual, this objection is still vulnerable to criticism. To restrict private property intellectual property rights would actually be self-undermining if one takes the Locke's concern for humanity to be the fundamental Lockean concern. Without private intellectual property rights, creators might not devote as much effort to creating intellectual products. This is admittedly an instrumentalist concern, but it is valid here because of the nature of the intellectual common. Common resources are themselves enriched as creators work to produce intellectual products.

There are numerous examples of copyrighted works that enriched, rather than diminished, the resources available to society. Take Nirvana's "Smells Like Teen Spirit" for example. By labouring to write and record that song, Nirvana rightfully gained property rights in it. No one could use that song without the permission of the group. But that did not preclude others from being influenced or inspired by it. Without Nirvana, the early-nineties explosion of grunge music would likely never have occurred. Nirvana helped to inspire a new movement in popular music, despite being granted exclusive copyrights in their music.

Locke's property theory has limits on appropriation such as the spoilage proviso and the "enough and as good" proviso to ensure that the common will not be overly depleted. Lockean intellectual property theory also needs limits. Allowing for perpetually inviolable property rights in intellectual products is not only counterintuitive but also potentially harmful. It is counterintuitive because humanity would be completely excluded from using intellectual products created in the distant past, and we would have to pay royalties for practically everything. It is potentially harmful insofar as society would not have access to certain intellectual products that would benefit society even when such exclusion no longer benefits the owner of such products. For example, if someone today created a vaccine for an infectious disease, that person would rightfully own her product. But in two-hundred years, society might have a need to distribute it without being able to get her permission. Perpetually inviolable intellectual property rights would not allow for unlicensed distribution.

But Lockean limits appear to be the most difficult aspect of Locke's property theory to adapt to intellectual products. This is because neither of Locke's provisos can limit intellectual property rights. The spoilage proviso fails because it depends on the natural process of spoilage. Locke explains that some goods are not limited by the spoilage proviso: for example diamonds. ${ }^{50}$ Intellectual products, like diamonds,

\footnotetext{
${ }^{49}$ Shiffrin, supra note 3 , at 156

${ }^{50}$ See LOCKE, SECOND TREATISE, supra note $1, \S 46$ (One can appropriate "a sparkling Pebble or a Diamond, and...he might heap up as much of these durable things as he pleased; the exceeding of the
} 
do not spoil in the same way that an apple does. In fact, intellectual products are perpetually durable. Thus, the spoilage proviso cannot provide a substantive limit on intellectual property rights.

And the "enough and as good" proviso does not limit intellectual property rights either. This proviso has two parts. The first is quantitative: one must leave enough of the resources behind in the common. The second is qualitative: one must not take the best resources and leave humanity with those that are not as good. But if an intellectual labourer is only rewarded with property rights in his product - the expression - and not some part of the common - the ideas - then the common is never depleted either quantitatively or qualitatively. The creation and appropriation of an intellectual product can add to but not take away from the intellectual common, so the "enough and as good proviso" does nothing to limit intellectual property rights.

Some Lockean theorists have tried to solve this problem by creatively adapting Locke's provisos to intellectual property. ${ }^{51}$ Their approach to Lockean limits relies on new ways of thinking about spoilage or harm to humanity. They admit that Locke's provisos do not naturally conform to the complexities of intellectual property, but instead of giving up the provisos, they change the meanings thereof. These creative adaptations are strained. They are so altered that they hardly resemble Locke's original provisos. But if a theorist is creating what amounts to an entirely new set of limits, then that theorist need not be tied to Locke's limits. One can develop a set of new limits that are better equipped to deal with the complexities of intellectual property, if that is the goal. One can create such limits in a Lockean way by embracing his dual concern for public and private rights.

Benjamin Damstedt tries to solve the problem of limits with the spoilage proviso. Damstedt argues that exclusive private intellectual property rights violate the spoilage proviso in that intellectual labourers do not achieve " "total money substitution,' [i.e.] the conversion into money of all units of a product of labour that an individual will not personally use." 52 This requirement of "total money substitution" depends on a particular reading of Locke's spoilage proviso. Damstedt argues that "the waste prohibition requires that each unit be put to some use or sold to retain a property right in the good." 53 His reading is not simply that individuals must not appropriate more than they can before spoilage, but that any good must be put to some fully effective use or converted into money if property rights are to be justifiably maintained.

There are two problems with Damstedt's interpretation of the spoilage proviso. First, Damstedt uses a much different meaning of "waste" than Locke's. He conspicuously calls the spoilage proviso the "waste prohibition," which might make the discrepancy less obvious. Locke's discussion of spoilage is about the kind of

bounds of his just Property not lying in the largeness of his Possession, but the perishing of any thing uselessly in it.").

${ }^{51}$ See Gordon, supra note 2; Damstedt, supra note 2.

${ }^{52}$ Damstedt, supra note 2, at 1197.

${ }^{53} \mathrm{Id}$. 
spoilage that organic materials are subject to. The proviso is not about effective use. That his theory allows for the hoarding up of infinite durable goods is evidence of this. ${ }^{54}$ Locke's spoilage proviso allows you to collect all the rocks that you want, even if other people want them, too. Since intellectual products are durable in the same way that gold is, Locke's theory does not require that they be converted into money. Intellectual products might even be able to function as money themselves. ${ }^{55}$

The second problem with Damstedt's reading is much more troubling. By requiring that the labourer not only use his product but fully use it, Damstedt creates a rule that is impossible to follow in practice. For intellectual goods, the number of potential uses of a product is indeterminable and so is the value of such uses to potential users. Therefore one cannot know whether the owner of an intellectual product has fully converted enough potential uses into money to satisfy the waste prohibition. One could respond by saying that fully converting potential uses of an intellectual product into money is impossible. But on that view, every intellectual property owner is constantly violating Damstedt's waste prohibition. And since Damstedt contends that if a property right violates the prohibition, that property right is no longer justifiable, no one could justify intellectual property rights at all. Either 1) the prohibition is only occasionally violated, in which case the indeterminable nature of fully effective use renders the prohibition inefficacious; or 2) the prohibition is constantly being violated, in which case there are no justified intellectual property rights to limit.

Wendy Gordon tries to solve the problem of Lockean limits by adapting the "enough and as good" proviso to intellectual property theory. Gordon argues that the proviso limits intellectual property rights in this way:

Creators should have property in their original works, only provided that such grant of property does no harm to other persons' equal abilities to create or to draw upon the pre-existing cultural matrix and scientific heritage. $^{56}$

Intellectual property rights are justified only if they do not harm other persons' access to the common. One might object that new expressions never hinder access to the common. But Gordon responds that in order to contribute to one's culture, one needs access to the ever advancing intellectual resources of that culture:

If there is only one culture... a person who wishes to contribute to it usually is required to use the tools of that culture. Giving first creators ownership over any aspect of the culture...may make a later creator less well off. $^{57}$

Accordingly, intellectual property rights that have the potential to do harm by prohibiting the use of necessary cultural tools are not justified.

\footnotetext{
${ }^{54}$ LOCKE, SECOND TREATISE, supra note 51.

${ }^{55} I d$., $\S 48$ (Locke argues that, to be used as money a good must be "both lasting and scarce.").

${ }^{56}$ Gordon, supra note 2, at 1563-4.

${ }^{57} \mathrm{Id}$. at 1570
} 
Gordon's attempt to adapt the "enough and as good" proviso to intellectual property theory has two problems of its own. First, there is a question as to whether the types of "harm" she is concerned with are harmful enough to merit consideration. She gives the following example: "Some poems, some ideas, some works of art, become 'part of me' in such a way that if I cannot use them, I feel I am cut off from a part of myself." 58 This kind of harm is not similar to the type of harm that not sharing food might cause. And if this type of harm is taken as the standard for limiting intellectual property rights, artists would too easily lose their rights when their work became "part of" those exposed to it: every time an artwork became "part of" someone looking at it, the artist could lose an exclusive right to her painting. Further, the ability of an artist to retain her rights in an intellectual product would vary inversely as 1) she shares her product with the public and 2) her product is susceptible to becoming "part of" those who experience it. Artists who want to retain intellectual property rights would be best served if they simply did not share their work, or if their work was less likely to incite deep personal connections. If artists fear that they may be expropriated because of the effect their work has on others, they might not produce the same quality of work that they might have otherwise. As a result, our culture could suffer. Gordon, who is concerned with the richness of our culture, would not want this to happen.

The second problem with Gordon's analysis is that her conception of harm does not produce significant limits even granting her redefinition of the proviso. Her reading of the proviso requires that everyone have equal access to the "pre-existing cultural matrix and scientific heritage." 59 So in order to violate the proviso, a property right must somehow hinder access to the common as it was before that property right existed. But the creation and appropriation of a new intellectual expression does not affect access to the pre-existing common in any way. Instead, a new intellectual product, which did not exist in the common or otherwise in the world, is created and privately owned. The common may even be enriched by the creation of a new form, which is not susceptible to appropriation.

Both Damstedt and Gordon work to adapt Locke's own provisos to Lockean intellectual property theory, but neither is successful in creating practical limits. This is because Locke's provisos do not adapt to intellectual property theory: intellectual products never spoil, and the common is never depleted. If limits are a necessary part of Lockean intellectual property theory, then those limits must be found elsewhere.

The state of nature does not provide reasonable limits that apply to copyright. This is a problem, since limits are intuitively good for society. But this problem has a solution. Locke says, "Civil Government is the proper Remedy for the Inconveniences of the State of Nature." ${ }^{\circ 0}$ So if the state of nature does not provide reasonable limits on intellectual property, then civil society can legislate to remedy that inconvenience.

\footnotetext{
${ }^{58} I d$. at 1569 .

${ }^{59} I d$. at 1570 (emphasis added).

${ }^{60}$ LOCKE, SECOND TREATISE, supra note $1, \S 13$
} 
Civil society is itself limited in that it can only legislate for the good of society. "The good of society" means both good for society as a whole and also good for individuals within society. This view accords with Locke's dual concern for public and private rights. Locke states that the "Legislative constituted by [society], can never be suppos'd to extend farther than the common good; but is obliged to secure every one's Property." ${ }^{\prime 11}$ Society's positive laws should govern for the common good while at the same time securing individual property rights.

There are two ways of harnessing Lockean principles to limit intellectual property. First, one could endeavour to develop a complete list of specific Lockean limits. This requires consideration of a vast array of limits and their place within a Lockean civil society. This approach has its advantages. By increasing the work on the theoretical end, it reduces the amount of necessary deliberation on any given issue. It eliminates the need to go back to Locke's texts in that one could merely look at the list of Lockean limits.

But it is unlikely that one could ever produce anything approaching an exhaustive list. Intellectual property, by its nature, is constantly being redefined. Imagine a set of Lockean limits that an intellectual property theorist might have developed one hundred years ago. The list would probably be useful in many respects, providing guidelines for the amount of material that one could quote from a book, for example. There are, however, some important contemporary issues that the century-old list would not address. How much material can a musician "sample" from another musician's recording? $?^{62}$ It is doubtful that anyone writing a century ago would have anticipated such a question. Similarly if one were to compose a list of limits today, that list would likely be insufficient for dealing with advancements in intellectual products. The list would quickly require some supplemental theoretical work.

The second option for creating Lockean limits is to outline a normative framework for limits, rather than cataloguing them all. This requires consideration of fundamental Lockean concerns and how they might be used to evaluate potential limits on intellectual property. This would not produce a list of specific limits but instead a tool for deliberation. Ideally, judges and legislators would use the Lockean normative framework to adapt the law to the needs of society as intellectual property evolves.

This has the advantage of being adaptable to the changing world of intellectual property. As new intellectual products give rise to new questions, the normative framework provides the context for new Lockean answers. In this way, it avoids the problems that riddle the first option. What is more, the first option's list requires a normative framework as society advances. Each problem that the list could not solve would necessitate consideration of the theoretical foundations for the

\footnotetext{
${ }^{61}$ Id. $\$ 131$

${ }^{62}$ For a discussion of sampling and copyright, see A. Dean Johnson, Music Copyrights: The Need For An Appropriate Fair Use Analysis In Digital Sampling Infringement Suits, 21 FLA. ST. U. L. REV. 135 (1993); Randy S. Kravis, Comment, Does a Song by any Other Name Still Sound as Sweet?: Digital Sampling and its Copyright Implications, 43 AM. U. L. REV. 231 (1993); Bruce J. McGiverin, Note, Digital Sound Sampling, Copyright and Publicity: Protecting Against the Electronic Appropriation of Sounds, 87 CoLUM. L. REV. 1723 (1987).
} 
Lockean limits on the list. So while the normative framework is viable over time, the exhaustive list becomes dependent on the normative framework behind it. As a result, the normative framework is what the intellectual property theorist should concern himself with.

The normative framework for Lockean limits is Locke's dual concern for public and private rights. When considering the extent to which a given property right should be limited, one should determine the extent to which such a limit would enhance or diminish public and private rights. This does not seem to be a very specific normative framework. But what it lacks in specificity, it makes up for in adaptability. Lockean limits can be tailored to the needs of particular societies, and different societies may develop different limits. Whether a society's limits on intellectual property are Lockean depend on whether the limits are the result of balancing public and private rights.

The example of copyright expiration can help to explain how lawmakers could utilize the Lockean normative framework. To determine whether copyrights should expire, one must consider the rights of both the individual and society. On the one hand, the intellectual labourer has a right to copyright protection. On the other hand, the public should not be perpetually excluded from a given intellectual product. It is in the individual's interest to have the copyright last as long as possible, but it is in the public's interest to gain unrestricted access to the intellectual product as quickly as possible. The best solution would be one that best balances the private copyright and the public access. Or, put another way, it is the solution that acknowledges what is best for society and its members. The Lockean balance would mandate expiration after a reasonable period of time because the public's right to access an intellectual product should not be hindered forever. The specific copyright term might depend on the product, but in all cases, the best balance calls for eventual expiration. Therefore Lockean intellectual property theory allows for at least expiration as a limit on intellectual property rights.

Going through a long list of how the Lockean normative framework would apply to different kinds of limits would be both tedious and counterproductive. There are too many potential limits to consider. But more importantly, the point of the normative framework is not to give a completed list of Lockean limits, but instead to provide the means for deliberation. Any attempt to enumerate all the limits that should be placed on intellectual property rights would be appropriate only for a given society at a given time. Any attempt at enumerating all the limits that should be placed on intellectual property rights would be appropriate only for a given society at a given time. Understanding what the Lockean framework is and how it might be applied is much more important than predicting all possible intellectual property disputes and resolving them before they occur.

The specific Lockean limits on intellectual property that should be enacted by civil society are not as significant as the normative guidelines for creating such limits. And Locke provides those guidelines by simultaneously embracing public and private rights. Lockean limits in intellectual property would be limits that take both private and public interests into account. They would not overly limit private rights, for the purpose of individuals entering into society is to ensure the protection 
of their individual rights. But at the same time, a Lockean approach to intellectual property would not grant private rights that are so strong as to do significant harm to society as a whole because society must legislate for the public good. Lockean limits would balance public and private rights by granting sufficiently strong private intellectual property rights while maintaining a robust public intellectual common.

This Lockean approach to copyright is removed by a few steps from Locke's property theory, which provokes the question: what makes it Lockean? Or, more generally, what makes any intellectual property theory Lockean? The most obvious answer-that this copyright theory is Lockean in that it draws from Locke's workis not very satisfying. Many approaches, even some that directly contradict fundamental Lockean concerns, could meet this standard. The best answers lies in those fundamental Lockean concerns. Minimally, a Lockean approach to intellectual property would need to adhere to the basic tenets of Locke's property theory: initial common ownership, labour-desert appropriation, and limits on appropriation. Beyond that, a theory is more aptly termed Lockean if it embraces Locke's dual concern for the individual's property rights and the good of society. Since my approach both adheres to the basic tenets and embraces Locke's dual concern, it is appropriately called a Lockean copyright theory.

\section{CONCLUSION}

In section IV, I constructed a Lockean approach to intellectual property theory that left room for fair use. In this section, I will explain how fair use fits into that theoretical space and what implications a Lockean approach to copyright has for intellectual property law.

The limits of Lockean rights in intellectual property are determined by considering both the public rights and private rights. Any limit on individual rights must be created only with society in mind, and any limit on public rights must be done for the individuals within society.

Lockean intellectual property can allow for fair use, provided that a given society agrees that fair use is good for society. Decisions such as this one, under a Lockean framework, are not to be made by the intellectual property theorist. Since fair use is a doctrine of civil society, it is up to society to decide. But there can be a place for fair use within a Lockean approach to intellectual property, and the normative guideline for determining whether fair use should be part of intellectual property law is the private/public fulcrum of rights that emerges out of Locke's dual concern for the individual and society.

McGowan says that one of the most attractive aspects of a Lockean approach to intellectual property theory is that "it cannot be criticized for making predictions that might not be true." 63 What he means is that Lockean intellectual property theory does not tend to solve every problem, and it dodges criticism by not attempt-

\footnotetext{
${ }^{63}$ McGowan, supra note 2, at 68.
} 
ing to solve the harder ones. He is right in one way, but wrong in another. Lockean intellectual property theory does not solve the hard problems, but it does provide the method for solution. Adopting a Lockean approach means justifying society's ability to consider for itself what is best for its public and private needs. Different societies may come to different decisions. What matters is that society is a political structure built on mutual consent wherein constituents actively participate in creating, or at least validating through acceptance, their laws. If fair use is good for society, then fair use has a place within Lockean intellectual property theory.

We value fair use. As such, any intellectual property theory that precludes fair use is unacceptable. Lockean intellectual property theory, despite criticisms, leaves room for fair use. We need only consider whether fair use appropriately balances public and private rights in our society. Lockean theory also leaves ample deliberative space. It is adaptable to the changing needs of societies as they develop. The key to any conundrum within a Lockean context is the balance of rights: if a given solution simultaneously respects private and public rights, then it is a viable one. Lockean intellectual property theory provides enough answers to be worth putting into practice, while not providing so many answers that it becomes over determined. 